GRASAS Y ACEITES, 63 (4),

OCTUBRE-DICIEMBRE, 423-431, 2012,

ISSN: 0017-3495

DOI: $10.3989 /$ gya.023212

\title{
Evaluation of the oil produced from lettuce crops cultivated under different irrigation conditions
}

\author{
By M. Hassan El-Mallah and S.M. EI-Shami*
}

\author{
Fats and Oil Department, National Research Centre, Dokki, Cairo, Egypt \\ *Corresponding author: saelshami @ yahoo.com
}

\section{RESUMEN}

Evaluación del aceite producido a partir de cosechas de lechugas cultivadas bajo diferentes condiciones de riego.

Tres muestras de semillas de lechuga (Lactuca Sativa LS10, LS20, LS30) se cultivaron bajo tres condiciones de riego (bien regado, normal y con deficiencia de agua, después de 10, 20 y 30 días, respectivamente) para evaluar sus aceites y ver hasta qué punto el aceite de la planta de lechuga resiste las condiciones de riego. Los aceites extraídos de las tres muestras de semillas se evaluó mediante la determinación de ocho perfiles de lípidos usando cromatografía líquida HPLC en conjunción con la cromatografía gaseosa GLC. Los aceites de las semillas de lechuga se caracterizan por un alto contenido en ácidos linoleico y oleico. De los triglicéridos determinados, los acilados con linoleico y oleico son los mayoritarios. Los perfiles de esteroles totales incluyen $\beta$-sitosterol (como componente principal), seguido por 7-estigmasterol, campesterol y 5-estigmasterol en todas las muestras de aceite de semillas de lechuga, pero con ligeras diferencias. Además, se determinaron los esteroles libres y acilados, y esterilglicosidos acilados y libres. Se encontró que los aceites de LS30 tiene el más alto contenido de tocoferoles, siendo el -tocoferol el único constituyente en todas las muestras de aceites de semillas de lechuga. Por otra parte, la posición 2 en las tres muestras de aceites de semillas de lechuga se acilan principalmente con los ácidos grasos insaturados $(98,6 \%)$, oleico y linoleico. De acuerdo con estos resultados, se puede concluir que las condiciones de riego no afectan a los componentes lipídicos del aceite y el aceite de la planta de lechuga resiste el proyecto de riego y sus perfiles de lípidos están en acuerdo con los de los aceites vegetales convencionales.

PALABRAS CLAVE: Ácidos grasos - Esteroles - Lechuga - Lípidos - Tocoferoles - Triglicéridos.

\section{SUMMARY}

Evaluation of the oil Produced from lettuce crop cultivated under three irrigation conditions.

Three oil lettuce seed samples (lactuca Sativa LS10, LS20, LS30) were cultivated under three irrigation conditions (well, normal and water deficient conditions, after 10, 20 and 30 days respectively) to evaluate their oils and to see to what extent the oil lettuce plant resists draught conditions. The oils extracted from the three seed samples were evaluated by determining eight lipid profiles using HPLC in conjunction with capillary GLC. Lettuce seed oils are characterized by high contents of linoleic and oleic acids. Of the triacyl glycerols determined, those containing linoleyl and oleyl acyles are the major ones. The whole sterol profiles include $\beta$-sitosterol (as major component) followed by 7-stigmasterol, campesterol and 5-stigmasterol, which were found in all the lettuce seed oil samples but with slight differences. Furthermore, sterol patterns of the free and acylated sterols, free and acylated sterylglycosides were determined. It was found that LS30 oil has the highest tocopherol content and $\alpha$-tocopherol is the only constituent in all the lettuce seed oil samples. On the other hand, the 2-position in the lettuce seed oil samples is mainly acylated by unsaturated fatty acids $(98.6 \%)$ namely, oleic and linoleic acids. According to these results, it can be concluded that irrigation conditions do not affect the lipid constituents of the oil and the oil lettuce plant resists draught and its lipid profiles are in agreement with those of conventional vegetable oils.

KEY-WORDS: Fatty acids - Lettuce - Lipids - Sterols Tocopherols - Triacylglycerols.

\section{INTRODUCTION}

The oil lettuce crop was widely used, on limited scale, as a source of dietary oil in the Upper of Egypt until the year of 1960. Its existence and usage could be traced back to ancient times especially in the hot climate areas for its high oil content. Due to the development of the oil industry and cultivation of vast areas with competing oil seed crops, the lettuce oil is no longer produced. Nowadays, it is cultivated in a limited area in the Upper Egypt in the winter season by intercropping with other crops. Egypt, like other developing countries of the arid and semi arid regions, faces a major problem of limited natural resources of good, quality water. Therefore, studies should be oriented towards solving this problem by cultivating oil crops which resist the draught conditions in the newly reclaimed soils. Accordingly, it may be a good idea to increase its cultivated area in the newly reclaimed soils (where there is a shortage of fresh water). Its cultivation in these soils will depend on its resistance to draught. Recently, The National Research Center (NRC) experimental station cultivated a limited area with oil lettuce (Lactuca Sativa) in Upper Egypt (Qena and Esna) under certain irrigation conditions.

Very few studies on the lipid profiles of lettuce seed oil have been reported. The fatty acid and sterol compositions of two Lactuca species, 
namely, scariola and saligna had been carried out (El-Din et al., 1987 and Rafi and Tufail, 1991). The fatty acids compositions of Prickly lettuce seed oil (Lactuca Scariola L.) were determined (Mekki et al., 1998 and Mekki and Orabi, 2007), and it was reported that linoleic acid is the major unsaturated fatty acid followed by oleic acid while linolenic acid was found in a small amount. The lipid profiles of Lactuca Scariola seed oil lettuce (fatty acids, triacylglycerol molecular species, tocopherols and whole sterols) were studied (El-Mallah et al., 2003). It was found that the oil was rich in linoleic $(61.1 \%)$ and the main triacylglycerol species were LLL, LLO, LLP and LOO (23.3, 20.7, 10.0 and $11.3 \%$ respectively). On the other hand, $\alpha$-tocopherol was the only tocopherol found. It was also found that it contains $\beta$-sitosterol, 7-stigmasterol, campesterol, and 5-stigmasterol as major components followed by avenasterol, spinasterol and isofucosterol (41.1, 21.2, 11.0, 9.9, 6.1, 4.2 and 2.0\% respectively).

The main objective of this study was to evaluate the oil from lettuce seeds (Lactuca Sativa) cultivated under three irrigation conditions (well watered conditions, normal and water deficient; every 10, 20 and 30 days respectively) by determining their lipid profiles as well as to find out the fatty acids occupying the 2-position and in a screening analysis program designed for searching for nonconventional sources of oils. Also, it was aimed to see to what extent oil lettuce plants resist the draught conditions.

\section{MATERIALS AND METHODS}

\subsection{Materials}

Three samples of lettuce oil seeds (Lactuca sativa, season 2008) were obtained from the National Research Center (NRC) experimental station in Esna, Aswan, Upper Egypt. The three lettuce seed samples were cultivated under three water irrigation conditions: well watered conditions (irrigation every10 days, LS10), normal irrigation (irrigation every 20 days, LS20) and water deficient (irrigation every 30 days, LS30). Two oil seeds belonging to sunflower (Helianthus annus, SFO) and cottonseed (Gossypium barbadense, Giza 74, CSO) were cultivated (under normal irrigation conditions) in the NRC experimental agriculture station (Qanater El-Khairiya), during the 2008 season.

An authentic sample of mixed fatty acids methyl esters (C14-C24 saturated and unsaturated) was purchased from Sigma Chemical Co. Anthroyl nitrile (1- and 9-) and the catalyst, used in the preparation of the anthroyl derivatives of sterols and sterylglycosides were kindly supplied by T. Murui, Nisshen Oil Mills, Japan. A sterol mixture from cottonseed oil (Gossypium barbadense cv. Giza 75) as a reference sample was laboratory prepared and its composition was cholesterol, campesterol, 5-stigmasterol, $\beta$-sitosterol, isofucosterol, and avenasterol $(0.4,9.0$, $2.1,84.0,4.0$ and 0.5 respectively).

\subsection{Methods}

\subsubsection{Oil extraction}

Three lots of each kind of seeds (LS10, LS20 and LS30) were supplied from the NRC experimental station. Each lot was ground separately to pass a 60-mesh size with an electric mill and directly extracted twice with chloroform methanol (2:1 by volume) in a waring blender (Official and Tentative methods, 1980). The extracts were combined (to get a representative sample), dried over anhydrous sodium sulphate and the solvent was removed from the filtrate using a rotary evaporator under reduced pressure at $50^{\circ} \mathrm{C}$. The oil samples were kept in tightly closed containers at $0^{\circ} \mathrm{C}$ (to protect them from autoxidation) until use.

The lipid patterns, namely fatty acids (FA), triacylglycerols (TAG), tocopherols $(T)$, whole oil sterols and sterols of the sterol lipid classes, namely free sterols (FS), aceylated sterols (AS), sterylglycosides (SG) and acylated sterylglycosides (ASG) were determined according to the methods mentioned below.

All the HPLC and GLC data recorded in the tables are the means of two successive single determinations.

\subsubsection{Fatty acids pattern}

An oil sample was converted into methyl esters via transesterification with $5 \%$ methanolic hydrogen chloride (Christie, 1973). The transesterification reaction was monitored with the help of TLC using silica gel plates and $\mathrm{n}$ - hexane/diethyl ether/acetic acid $(80 / 20 / 1, V / V / V)$ as a developing solvent. A Hewlett Packard-HP 5980-A gas chromatograph was used for the analysis of the mixed FA methyl esters under the following operating conditions: column, DB-23 $(0.32 \mathrm{~mm} \times 30 \mathrm{~m})$; temperature programming, $150-230^{\circ} \mathrm{C}, 3^{\circ} \mathrm{C} \mathrm{min}^{-1}$; injector, $230^{\circ} \mathrm{C}$; detector, FID at $240^{\circ} \mathrm{C}$; carrier gas, Helium at a flow rate of $1.3 \mathrm{~mL} \mathrm{~min}^{-1}$ and split ratio of $100 / 1$. Calibration was made using standard fatty acid methyl esters.

\subsubsection{Triacylglycerols profile}

An HPLC instrument (Toyo-Soda-CCPM) was employed for the determination of TAG profiles of the oils of LS10, LS20, LS30, SBO and CSO. A 10 $\mu \mathrm{L}$ solution of oil in chloroform (300 $\left.\mathrm{mg} \mathrm{m}^{-1}\right)$ was injected into the column, ODS capsel Pak, C18 (4.4 $\mathrm{mm} \times 10 \mathrm{~cm})$. Gradient elution with acetonitrile: dichloromethane (starting from 90:10 to $35: 65 \mathrm{v} / \mathrm{v}$ ) in 150 minutes was conducted. A FID detector (with 
moving band, Tracor 945) was attached to the instrument.

The carbon number assignment for the separated peaks was determined using an HPLC chromatogram for soybean oil (SBO) taken as reference containing 29 TAG starting with trilinolenin ( $L n L n L n)$ and ending with with tristearin (SSS) (El-Mallah et al., 1994 and El-Mallah et al., 1999). The eluted TAG's were separated according to their equivalent carbon number (ECN) or critical pairs. The elution sequence was the same as that reported by (El-Hamdy and Perkins, 1981). The following coding for fatty acyls was used: Ln (linolenic), L (linoleic), O (oleic), S (stearic) and P (palmitic acid).

\subsubsection{Whole sterol profile}

The unsaponifiable portion of the oil was prepared (Official and Tentative Methods, 1980). An accurately weighed sample of the unsaponifiable matter was subjected to preparative TLC on silica gel $\mathrm{G}$ plates (0.5 mm thickness) using chloroform/ diethyl ether/ acetic acid (95/4/1 by volume) as a developing solvent. The sterol zone was located with the help of standard $\beta$-sitosterol applied alongside the sample prior to development. The sterol zone was scraped off the plate and thoroughly extracted with moistened diethyl ether and the solvent was evaporated.

The sterol mixture of the sample and the reference were separately converted into trimethylsilyl derivatives (TMS) (Christie, 1973).

A Hewlett Packard-HP 5890-A gas chromatograph was employed for the analysis using the following operating conditions: Column, DB-17 (0.32 mm $\times 15 \mathrm{~m}, 0.25 \mu \mathrm{m}$ coating) at $250^{\circ} \mathrm{C}$; detector, FID at $260^{\circ} \mathrm{C}$; injection, at $250^{\circ} \mathrm{C}$; carrier gas, Helium ( $8.6 \mathrm{~mL} \mathrm{~min}^{-1}$ ) and split ratio, $35: 1$. The TMS of the sterol reference (containing known percentages of sterols) was used for the identification and quantification of the sterols in each oil sample.

\subsubsection{Free and acylated sterol patterns (FS and $A S$ )}

The FS and AS isolations, their derivatization into 9-anthroylnitrile (S-9-AN) and HPLC determination, were carried out (El-Mallah et al., 1994; El-Mallah et al., 1999 and Wanaka and Murui, 1992). FS and AS were isolated from the oil by preparative TLC using n-hexane/diethyl ether/ formic acid (70/30/1, v/ v/v) as developing solvent. The FS $(R f=0.16)$ and $A S(R f=0.63)$ were scraped off the plate and extracted with chloroform. Only AS were deacylated via mild alkaline hydrolysis $(0.5 \mathrm{~N}$ $\mathrm{KOH}$ in isopropyl alcohol). The obtained FS as well as the original FS were separately derivatized into their S-9-AN derivatives according the above mentioned reported methods. HPLC analysis of the S-9-AN was conducted under the following conditions: reversed phase column, ODS-1250Y, Senshu Pak (4.6 mm × $250 \mathrm{~mm}$ ); detector, fluorescence; excitation and emission, wave lengths set at 360 and $460 \mathrm{~nm}$; isocratic elution using acetonitrile/ dichloromethane $(75 / 25, \mathrm{v} / \mathrm{v})$ at a flow rate of $1 \mathrm{~mL} \mathrm{~min}^{-1}$. The identification of the peaks was designated as reported (Murui et al., 1993).

\subsubsection{Free and acylatedsSterylglycosides profile (FSG and $A S G$ )}

The procedure of separation of FSG and ASG from the oil, their derivatization into sterylglycoside1-anthroylnitrile (SG-1-AN) and HPLC analysis were carried out (El-Mallah et al., 1994; El-Mallah et al., 1999 and Murui et al., 1992).

An HPLC instrument equipped with a UV detector (Tosoh, UV 8000) and ODS Wakosil-5 C18 $(6.4 \mathrm{~mm} \times 250 \mathrm{~mm})$ was used for SG-1-AN analysis. Gradient elution with acetonitrile/ dichloromethane (from 50/50 to $68 / 32 \mathrm{v} / \mathrm{v}$ ) was used. The absorbance was measured at $254 \mathrm{~nm}$. The identification of the peaks was designated as reported by (Murui et al., 1993).

\subsubsection{Tochopherol pattern}

The direct determination of tocopherols $(T)$ in the oil samples as well as in the standard tocopherol mixture (with a known weight of each individual) was accomplished using Toyo-Soda-CCPM HPLC instrument. A solution of $10 \%$ oil in hexane was prepared and $10 \mu \mathrm{L}$ of this solution were injected into the silica column (YMC-A-012, $6.0 \mathrm{~mm} \times 150$ $\mathrm{mm})$. Isocratic elution was conducted using n-hexane: isopropyl alcohol (100:0.5 by volume) as a mobile phase at a flow rate of $2 \mathrm{~mL} \mathrm{~min}^{-1}$. A Hitachi-650-10S fluorescence detector was used. Spectral absorption was set at excitation and emission wavelengths of 295 and $325 \mathrm{~nm}$ respectively. The conditions were optimized to elute $\delta$-T after 10 minutes. The results were automatically recorded as peak area percentages using an electronic integrator. From the peak area and the corresponding weight of each individual $T$ in the standard mixture, the weight of each individual $T$ in the oil (ppm) can be calculated (ElMallah et al., 1994, and El-Shami et al., 1994).

\subsubsection{Lipolysis}

The technique of pancreatic lipase hydrolysis (Osman et al., 1973) was applied on LS30 (as representative of the lettuce seed oils) in an attempt to determine the fatty acids occupying the 2-position and to see whether lettuce seed oil is compatible with the conventional vegetable oils in distribution of the fatty acyl moities. The product after lipolysis was separated by preparative TLC into mono-, di-, tri- glyceride and free fatty acid fractions. The former fraction was scraped off the plate, extracted 
with moistened diethyl ether, evaporated to dryness, saponified with alcoholic potassium hydroxide, acidified with $\mathrm{HCl}$ and the liberated fatty acids were extracted with diethyl ether. The produced fatty acid mixture was converted to methyl esters (Christie, 1973) and subjected to GLC analysis for their fatty acid compositions, as mentioned before, to see which fatty acids occupy the 2-position.

\subsubsection{Statistical analysis}

All results were evaluated statistically using analysis of variance as reported by McClave and Benson (1991).

\section{RESULTS}

\subsection{Fatty acid composition}

The fatty acid compositions of LS10, LS20 and LS30 seed oils as well as those of SFO and CSO are recorded in Table 1. It was observed that lettuce oils were rich in linoleic acid (61.23, 62.50 and 62.45 for LS10, LS20 and LS30 respectively) followed by oleic acid $(26.90,25.80$ and 26.10 respectively) but contained minute amounts of linolenic acid $(0.27,0.25$ and 0.20 in the three lettuce oils). SFO and CSO contained comparatively low amounts of linoleic acid (43.51 and 49.45 respectively). Oleic acid was generally much lower than that of SFO $(44.6 \%)$ but higher than that of CSO (18.96\%). It seems that lettuce oils improve their stability which is comparable to that of SFO and CSO.

\subsection{Triacylglycerols molecular species}

The HPLC analysis of theTAG species of LS10, LS20 and LS30 oils as well as SFO and CSO (Table 2) shows the presence of about 28 TAGs containing palmitic, stearic, oleic, linoleic and linolenic acyl groups. TAGs with lower ECN eluted ahead of those with higher ECN and the elution sequence within each TAG category having the same ECN (critical pairs) started with the highest number of double bonds and ended with the lowest unsaturation (El-Hamdy and Perkins, 1981). The designation of TAGs does not imply the positional acyl distribution in the TAG molecules, but a mixture of TAG isomers. The major TAGs were those containing linolyl and oleyl acyles, namely, LLL, LLO, LLP and LOO, respectively (having 6, 5, 4 and 4 double bonds, respectively) followed by LOP (containing 3 double bonds). Other TAGs, namely LLS, OOO, LOS, OOP and OOS (containing 4, 3, 3,2 and 2 double bonds respectively) were present in appreciable amounts. LLL, LLO, LOO and LLS were the major TAGs in SBO. In the case of CSO, LLL, LLO, LLP, LOP and LPP were major. It could be seen that lettuce seed oils resemble both SFO and CSO in some of the major TAGs.

\subsection{Whole sterols pattern}

From the results obtained (Table 3 ), it was found that $\beta$-sitosterol was the major constituent followed by 7 -stigmasterol, campesterol and 5-stigmasterol, whereas ergosterol, spinasterol, isofucosterol and avenasterol were found in reasonable amounts in all lettuce seed oils but with slight differences. On the other hand, $\beta$-sitosterol was also the major constituent in SFO followed by 7-stigmasterol, 5-stigmasterol, and campesterol whereas $\beta$-sitosterol constituted $81.30 \%$ of the total sterols of CSO followed by campesterol.

\subsection{Sterol pattern of free and acylated sterols}

Sterols are present in vegetable oils in two forms, namely free and acylated sterols. The HPLC results of FS and AS are recorded in Table 4. The total contents of FS and AS, isolated from the oils, were 310,320 , and $314 \mathrm{mg} 100 \mathrm{~g}^{-1}$ oil for LS10, LS20, and LS30 oils, respectively. Among the lettuce oils, LS10 contained the highest amount of

Table 1

Fatty acid composition

\begin{tabular}{|c|c|c|c|c|c|c|c|c|c|c|c|c|}
\hline \multirow{3}{*}{$\begin{array}{c}\text { Oil } \\
\text { sample }\end{array}$} & \multicolumn{12}{|c|}{ Fatty Acid Composition (\%) } \\
\hline & \multirow{2}{*}{$14: 0$} & \multirow{2}{*}{$16: 0$} & \multirow{2}{*}{$16: 1$} & \multirow{2}{*}{ 18:0 } & \multicolumn{2}{|c|}{$18: 1$} & \multirow{2}{*}{$18: 2$} & \multirow{2}{*}{$18: 3$} & \multirow{2}{*}{ 20:0 } & \multirow{2}{*}{$20: 1$} & \multirow{2}{*}{$22: 0$} & \multirow{2}{*}{$24: 0$} \\
\hline & & & & & $n-9$ & $n-7$ & & & & & & \\
\hline LS 10 & $0.0866 \pm 0.02$ & $6.00 \pm 0.1$ & $0.25^{a} \pm 0.01$ & $3.50 \pm 0.1$ & $26.3^{\mathrm{a}} \pm 0.1$ & $0.60 \pm 0.1$ & $61.23^{c} \pm 0.00$ & $0.27^{\mathrm{a}} \pm 0.01$ & $1.20^{2} \pm 0.015$ & $0.27 \pm 0.01$ & $0.28^{\mathrm{a}} \pm 0.01$ & n.d \\
\hline LS20 & $0.099 \pm 0.03$ & $6.10 \pm 0.3$ & $0.15^{b} \pm 0.01$ & $3.55 \pm 0.1$ & $25.07^{\circ} \pm 0.15$ & $0.70 \pm 0.02$ & $62.50^{\mathrm{a}} \pm 0.001$ & $0.25^{b} \pm 0.01$ & $1.00^{b} \pm 0.01$ & $0.25 \pm 0.01$ & $0.25^{b} \pm 0.01$ & n.d \\
\hline LS30 & $0.10 \pm 0.2$ & $6.30 \pm 0.25$ & $0.15^{b} \pm 0.01$ & $3.40 \pm 0.1$ & $25.54^{b} \pm 0.00$ & $0.56 \pm 0.01$ & $62.45^{b} \pm 0.00$ & $0.20^{c} \pm 0.01$ & $0.90^{b} \pm 0.01$ & $0.20 \pm 0.01$ & $0.20^{c} \pm 0.01$ & n.d \\
\hline L.S.D 5\% & & & 0.01998 & & 0.21096 & & 1.9971 & 0.01997 & 0.1641 & & 0.01998 & \\
\hline SFO & $0.15 \pm 0.001$ & $6.00 \pm 0.2$ & $0.14 \pm 0.001$ & $3.50 \pm 0.001$ & $44.00 \pm 0.1$ & $0.60 \pm 0.001$ & $43.51 \pm 0.0105$ & n.d & $0.35 \pm 0.001$ & $0.25 \pm 0.001$ & $1.00 \pm 0.1$ & $0.50 \pm 0.01$ \\
\hline CSO & $1.00 \pm 0.1$ & $25.00 \pm 0.1$ & $0.80 \pm 0.1$ & $3.30 \pm 0.01$ & $17.96 \pm 0.001$ & $1.00 \pm 0.1$ & $49.45 \pm 0.001$ & $0.35 \pm 0.001$ & $0.44 \pm 0.001$ & n.d & $0.40 \pm 0.00$ & $0.30 \pm 0.001$ \\
\hline
\end{tabular}

n.d: Not detected.

Each value is the mean $\pm S D$ of three triplicate determinations.

Means in each column with different letters are significantly different $(p<0.05)$. 
Table 2

HPLC analysis of triacylglycerol molecular species

\begin{tabular}{|c|c|c|c|c|c|c|c|}
\hline \multirow{2}{*}{ TAG } & \multicolumn{7}{|c|}{ Triacylglycerols \% } \\
\hline & ECN & LS10 & LS20 & LS30 & L.S.D & SFO & cso \\
\hline LnLnLn & 36 & n.d & n.d & n.d & & n.d & n.d \\
\hline LnLnL & 38 & n.d & n.d & n.d & & n.d & $0.5 \pm 0.049$ \\
\hline LnLL & 40 & $0.2 \pm 0.1$ & $0.4 \pm 0.0999$ & $0.4 \pm 0.0999$ & & $0.2 \pm 0.1$ & n.d \\
\hline LnLnO & 40 & n.d & n.d & n.d & & n.d & n.d \\
\hline LnLnP & 40 & n.d & n.d & n.d & & n.d & n.d \\
\hline LLL & 42 & $24.3^{a} \pm 0.09974$ & $24.17^{a} \pm 0.15$ & $23.633 \pm 0.66$ & & $19.4 \pm 0.1$ & $12.0 \pm 0.099$ \\
\hline LnLO & 42 & $0.3 \pm 0.01$ & $0.4 \pm 0.0999$ & $0.40 \pm 0.0999$ & & $0.2 \pm 0.01$ & n.d \\
\hline LnLP & 42 & - & - & - & & $0.1 \pm 0.00999$ & $0.1 \pm 0.0099$ \\
\hline LnLnS & 42 & n.d & n.d & n.d & & n.d & n.d \\
\hline LLO & 44 & $19.4^{c} \pm 0.1$ & $20^{\mathrm{b}} \pm 0.1$ & $20.7^{\mathrm{a}} \pm 0.0997$ & 0.1995 & $21.4 \pm 0.1$ & $12.5 \pm 0.1$ \\
\hline LnOO & n.d & n.d & n.d & n.d & & n.d & n.d \\
\hline LLP & 44 & $10.1^{b} \pm 0.099$ & $10.5^{\mathrm{a}} \pm 0.099$ & $10.0^{b} \pm 0.1$ & 0.1996 & n.d & $22.0 \pm 0.1$ \\
\hline LnLS & 44 & n.d & n.d & n.d & & $8.5 \pm 0.1$ & n.d \\
\hline LnOP & 44 & n.d & n.d & n.d & & n.d & $1.5 \pm 0.1$ \\
\hline Uk.1 & & $0.2 \pm 0.01$ & $0.5 \pm 0.01$ & $0.3 \pm 0.01$ & & n.d & n.d \\
\hline LnPP & 44 & n.d & n.d & n.d & & n.d & n.d \\
\hline LOO & 46 & $11.3^{\mathrm{a}} \pm 0.1$ & $10.97^{b} \pm 0.153$ & $11.3^{a} \pm 0.099$ & & $20.5 \pm 0.058$ & $6.0 \pm 0.099$ \\
\hline LLS & 46 & $3.8 \pm 0.1$ & $3.7 \pm 0.09$ & $3.8 \pm 0.1$ & & $13.2 \pm 0.1$ & n.d \\
\hline LOP & 46 & $7.69^{b} \pm 0.1$ & $8.0^{a} \pm 0.1$ & $7.4^{c} \pm 0.099$ & 0.1997 & n.d & $16.5 \pm 0.099$ \\
\hline LPP & 46 & $2.2^{a} \pm 0.099$ & $0.4^{b} \pm 0.099$ & $2.3^{a} \pm 0.1$ & 0.1997 & $1.4 \pm 0.1$ & $12.97 \pm 0.057$ \\
\hline Uk. 2 & & $0.2 \pm 0.01$ & $0.3 \pm 0.01$ & $0.3 \pm 0.01$ & & n.d & n.d \\
\hline O०० & 48 & $4.9^{\mathrm{a}} \pm 0.099$ & $4.3^{c} \pm 0.1$ & $4.6^{b} \pm 0.1$ & 0.1998 & $3.9 \pm 0.1$ & $1.9 \pm 0.1$ \\
\hline Uk. 3 & & $1.4 \pm 0.1$ & $1.7 \pm 0.05774$ & $1.5 \pm 0.1$ & & n.d & n.d \\
\hline LOS & 48 & $3.9^{a} \pm 0.1$ & $3.9^{a} \pm 0.1$ & $3.6^{b} \pm 0.1$ & 0.1998 & $4.6 \pm 0.1$ & $1.5 \pm 0.1$ \\
\hline OOP & 48 & $3.7^{a} \pm 0.0999$ & $3.2^{c} \pm 0.0999$ & $3.5^{\mathrm{b}} \pm 0.1$ & 0.1997 & $1.8 \pm 0.099$ & $3.5 \pm 0.1$ \\
\hline LSP & 48 & $0.8 \pm 0.099$ & $0.9 \pm 0.099$ & $0.8 \pm 0.099$ & & $1.1 \pm 0.1$ & $2.4 \pm 0.1$ \\
\hline POP & 48 & $0.4 \pm 0.099$ & $0.4 \pm 0.099$ & $0.5 \pm 0.1$ & & $0.2 \pm 0.1$ & $5 \pm 0.1$ \\
\hline LnSS & 48 & n.d & n.d & n.d & & & n.d \\
\hline PPP & 48 & $0.3 \pm 0.1$ & $0.4 \pm 0.099$ & $0.4 \pm 0.099$ & & n.d & $0.2 \pm 0.1$ \\
\hline Uk.4 & & $1.5 \pm 0.1$ & $1.4 \pm 0.1$ & $1.3 \pm 0.1$ & & n.d & n.d \\
\hline oos & 50 & $2.0^{a} \pm 0.099$ & $1.7^{b} \pm 0.0991$ & $1.9^{\mathrm{a}} \pm 0.1$ & & $2.1 \pm 0.099$ & $0.2 \pm 0.1$ \\
\hline LSS & 50 & $0.5 \pm 0.1$ & $0.4 \pm 0.1$ & $0.5 \pm 0.1$ & & $0.5 \pm 0.1$ & $0.1 \pm 0.0099$ \\
\hline POS & 50 & $0.5 \pm 0.1$ & $0.4 \pm 0.0999$ & $0.5 \pm 0.1$ & 0.1629 & $0.5^{\mathrm{a}} \pm 0.1$ & $0.1 \pm 0.0099$ \\
\hline Uk. 5 & & $0.1 \pm 0.01$ & $0.1 \pm 0.01$ & n.d & & n.d & n.d \\
\hline SPP & 50 & $0.3^{a} \pm 0.1$ & $0.3^{a} \pm 0.1$ & $0.1^{\mathrm{b}} \pm 0.0099$ & 0.1338 & n.d & $0.1 \pm 0.0099$ \\
\hline sos & 50 & $0.3 \pm 0.1$ & $0.2 \pm 0.1$ & $0.3 \pm 0.1$ & & n.d & n.d \\
\hline SSP & 50 & $0.1 \pm 0.0099$ & $0.1 \pm 0.0099$ & $0.2 \pm 0.1$ & & n.d & n.d \\
\hline Uk.6 & & $0.7 \pm 0.02082$ & $0.6 \pm 0.1$ & $1.2 \pm 0.1$ & & n.d & n.d \\
\hline Uk.7 & & $0.2 \pm 0.01$ & $0.1 \pm 0.01$ & n.d & & n.d & n.d \\
\hline
\end{tabular}

n.d: Not detected.

Each value is the mean \pm SD of three triplicate determinations.

Means in each column with different letters are significantly different $(p<0.05)$. 
Table 3

GLC of whole sterol profiles as silyl derivatives

\begin{tabular}{|c|c|c|c|c|c|c|c|c|c|}
\hline \multirow{2}{*}{$\begin{array}{c}\text { Oil } \\
\text { Sample }\end{array}$} & \multirow{2}{*}{ 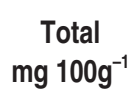 } & \multicolumn{8}{|c|}{ Whole Sterol Composition (\%) } \\
\hline & & Campesterol & 5-Stigmasterol & Ergosterol & $\beta$-sitosterol & Spinasterol & Isofucosterol & 7-Stigmasterol & Avenasterol \\
\hline LS10 & $450^{\circ} \pm 5$ & $11.0^{\mathrm{a}} \pm 0.5$ & $9.9 \pm 0.1$ & $4.5^{b} \pm 0.1$ & $41.1^{a} \pm 0.1$ & $4.2 \pm 0.1$ & $2.0 \pm 0.1$ & $21.2^{c} \pm 0.1$ & $6.1^{c} \pm 0.1$ \\
\hline LS20 & $500^{b} \pm 5$ & $9.80^{b} \pm 0.1$ & $10.0 \pm 1$ & $4.7^{\mathrm{a}} \pm 0.1$ & $40.1^{b} \pm 0.1$ & $4.0 \pm 0.1$ & $2.1 \pm 0.1$ & $22.4^{b} \pm 0.1$ & $6.9^{\mathrm{a}} \pm 0.1$ \\
\hline LS30 & $550^{\mathrm{a}} \pm 5$ & $10.3^{b} \pm 0.1$ & $9.8 \pm 0.1$ & $4.8^{\mathrm{a}} \pm 0.1$ & $39.7^{c} \pm 0.1$ & $4.2 \pm 0.1$ & $1.9 \pm 0.1$ & $22.63^{\mathrm{a}} \pm 0.1$ & $6.7^{b}$ \\
\hline L.S.D & 9.9898 & 0.5994 & - & 0.1998 & 0.19908 & - & - & 0.1775 & 0.1998 \\
\hline SFO & $430 \pm 10$ & $9.1 \pm 0.1$ & $11.1 \pm 0.1$ & n.d & $60.4 \pm 0.1$ & n.d & $3.5 \pm 0.1$ & $11.7 \pm 0.1$ & $4.2 \pm 0.1$ \\
\hline cso & $450 \pm 5$ & $10.0 \pm 1$ & $3.0 \pm 0.1$ & n.d & $81.3 \pm 0.1$ & n.d & $5.0 \pm 0.1$ & n.d & $0.7 \pm 0.1$ \\
\hline
\end{tabular}

n.d: Not detected

Each value is the mean $\pm S D$ of three triplicate determinations.

Means in each column with different letters are significantly different $(p<0.05)$

Table 4

Composition of free and acylated sterols as 9-AN-derivatives

\begin{tabular}{|c|c|c|c|c|c|c|c|c|c|c|c|c|c|c|c|}
\hline \multirow{3}{*}{ Oil } & \multirow{2}{*}{\multicolumn{3}{|c|}{$\begin{array}{l}\text { Total content } \\
\mathrm{mg} 100 \mathrm{~g}^{-1}\end{array}$}} & \multicolumn{12}{|c|}{ Free and acylated sterol compositions ( $\%$ ) } \\
\hline & & & & \multicolumn{2}{|c|}{ Avenasterol } & \multicolumn{2}{|c|}{ Isofucosterol } & \multicolumn{2}{|c|}{ Spinasterol } & \multicolumn{2}{|c|}{$\begin{array}{c}\text { Campesterol + } \\
\text { Stigmasterol }\end{array}$} & \multicolumn{2}{|c|}{ 7-Stigmasterol } & \multicolumn{2}{|c|}{$\beta$-Sitosterol } \\
\hline & FS & AS & Total & FS & AS & FS & AS & FS & AS & FS & AS & FS & AS & FS & AS \\
\hline LS10 & $240 \pm 5$ & $70^{b} \pm 5$ & $310 \pm 5$ & $4.5^{\complement} \pm 0.1$ & $6.0 \pm 1$ & $4.2^{b} \pm 0.1$ & $8.8^{\mathrm{a}} \pm 0.1$ & Trace & Trace & $28.3^{\mathrm{a}} \pm 0.1$ & $9.6^{a} \pm 0.1$ & $14.0^{b} \pm 0.1$ & $43.2^{b} \pm 0.1$ & $49.0^{b} \pm 0.2$ & $32.4^{\mathrm{a}} \pm 0.1$ \\
\hline LS20 & $237 \pm 1$ & $83^{\mathrm{a}} \pm 1$ & $320 \pm 5$ & $6.1^{b} \pm 0.1$ & $7.3 \pm 0.1$ & $3.2^{c} \pm 0.1$ & $8.2^{b} \pm 0.1$ & Trace & Trace & $28.3^{\mathrm{a}} \pm 0.1$ & $7.5599^{\mathrm{a}} \pm 0.1$ & $14.7^{\mathrm{a}} \pm 0.1$ & $45.8^{\mathrm{a}} \pm 0.1$ & $48.1^{c} \pm 0.1$ & $31.2^{c} \pm 0.1$ \\
\hline LS30 & $235 \pm 1$ & $79^{\mathrm{a}} \pm 1$ & $314 \pm 1$ & $6.6^{a} \pm 0.1$ & $5.57 \pm 0.15$ & $7.4^{\mathrm{a}} \pm 0.1$ & $8.099^{b} \pm 0.1$ & Trace & Trace & $27.3^{b} \pm 0.1$ & $8.2^{b} \pm 0.1$ & $9.1^{c} \pm 0.1$ & $45.8^{a} \pm 0.1$ & $49.6^{a} \pm 0.1$ & $32.2^{b} \pm 0.1$ \\
\hline L.S.D & - & - & - & 0.19979 & - & 0.19977 & 0.1998 & & & 0.19989 & 0.19989 & 0.19989 & 0.1974 & 0.2815 & 0.19908 \\
\hline Sunflower & $190 \pm 5$ & $60 \pm 1$ & $250 \pm 5$ & $3.5 \pm 0.1$ & $4.2 \pm 0.1$ & $5.8 \pm 0.1$ & $3.0 \pm 0.1$ & $2.0 \pm 0.1$ & $1.7 \pm 0.1$ & $18.5 \pm 0.1$ & $24.5 \pm 0.1$ & n.d & $5.0 \pm 0.1$ & 70.2 & $61.6 \pm 1$ \\
\hline Cottonseed & $1,200 \pm 2.9$ & $400 \pm 7.6$ & $1,600 \pm 5$ & $1.0 \pm 0.1$ & $1.6 \pm 0.1$ & $8.0 \pm 0.1$ & $10.0 \pm 0.1$ & $0.3 \pm 0.01$ & $0.2 \pm 0.01$ & $8.7 \pm 0.1$ & $12.0 \pm 0.1$ & n.d & n.d & $82.0 \pm 1$ & $76.2 \pm 1$ \\
\hline
\end{tabular}

AN: Anthroylnitrile; FS: Free sterol and AS: Acylated sterol

n.d: Not detected.

Each value is the mean \pm SD of three triplicate determinations.

Means in each column with different letters are significantly different $(p<0.05)$

FS. On the other hand, LS20 contained the highest amount of AS as well as the highest total amount $(A S+F S)$. The FS and AS profiles showed the presence of avenasterol, isofucosterol, campesterol/stigmasterol (unseparable pair), 7 -stigmasterol and $\beta$-sitosterol in the lettuce oils as well as SFO but at different levels. LS30 was distinguished from LS10 and LS20 in having markedly higher percentages of avenasterol and isofucosterol in the FS fraction. On the other hand, sunflower and cottonseed oils were distinguished by higher amounts of $\beta$-sitosterol in both AS and FS fractions in comparison with the lettuce oils. In addition, 7-stigmasterol was absent in both fractions of CSO and in the FS fraction of SNO. It was also noted that the lettuce oils were characterized by high contents of free sterols.

\subsection{Sterol pattern of free and acylated sterylglycosides}

The results recorded in Table 5 show the total contents of FSG and ASG in the five oils under investigation as ppm. LS10 was distinguished by the highest content of total SG in comparison with LS20 and LS30. It was found that $\beta$-sitosterol was the major component in both fractions followed by campesterol/stigmasterol pair in the five oils. It was also found that the lettuce seed oils were distinguished from the conventional oils in having spinasterol (absent in SFO and CSO) in reasonable amounts in both fractions. SFO and CSO contained markedly lower amounts of total SG than the lettuce seed oils. On the other hand, CSO contained low amounts of campe/stigma sterol in both fractions in comparison with the lettuce seed oils.

\subsection{Tocopherol pattern}

The tocopherol profiles as well as their contents in LS10, LS20, LS30, SFO, and CSO oils are illustrated in Table 6. It can be seen that LS30 oil had the highest tocopherol content $\left(390 \mathrm{mg} \mathrm{kg}^{-1}\right)$ in comparison with LS10 and LS20 (381 and $385 \mathrm{mg}$ $\mathrm{kg}^{-1}$ respectively). Alpha-tocopherol was the only component of the tocopherol profiles of all lettuce 
Table 5

Composition of free and acylated sterylglycosides as 1-AN-derivatives

\begin{tabular}{|c|c|c|c|c|c|c|c|c|c|c|c|c|c|c|c|}
\hline \multirow{3}{*}{$\begin{array}{l}\text { Selected } \\
\text { Oils }\end{array}$} & \multirow{2}{*}{\multicolumn{3}{|c|}{ 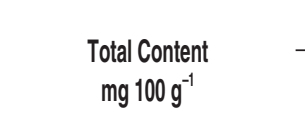 }} & \multicolumn{12}{|c|}{ Free and Acylated sterylglycosides $\%$} \\
\hline & & & & \multicolumn{2}{|c|}{$\begin{array}{c}\text { Avenasterol } \\
\text { SG }\end{array}$} & \multicolumn{2}{|c|}{$\begin{array}{l}\text { Isofucosterol } \\
\text { SG }\end{array}$} & \multicolumn{2}{|c|}{$\begin{array}{l}\text { Spinasterol } \\
\text { SG }\end{array}$} & \multicolumn{2}{|c|}{$\begin{array}{c}\text { Campesterol + } \\
\text { Stigmasterol SG }\end{array}$} & \multicolumn{2}{|c|}{$\begin{array}{c}\text { 7-Stigmasterol } \\
\text { SG }\end{array}$} & \multicolumn{2}{|c|}{$\begin{array}{c}\beta \text {-Sitosterol } \\
\text { SG }\end{array}$} \\
\hline & FS & AS & Total & FS & AS & FS & AS & FS & AS & FS & AS & FS & AS & FS & AS \\
\hline LS10 & $675^{a} \pm 5$ & $642^{b} \pm 1$ & $1,317^{a} \pm 5$ & $1.8^{b} \pm 0.1$ & $1.7^{b} \pm 0.1$ & $2.5^{b} \pm 0.1$ & $2.8^{b} \pm 0.1$ & $4.7^{\mathrm{a}} \pm 0.1$ & $4.3^{c} \pm 0.1$ & $26.0 \pm 0.1$ & $26.0^{b} \pm 0.1$ & $9.3 \pm 1$ & $7.5 \pm 0.1$ & $56.7^{b} \pm 0.1$ & $57.2^{\mathrm{a}} \pm 0.1$ \\
\hline LS20 & $589^{b} \pm 1$ & $668^{\mathrm{a}} \pm 1$ & $1,257^{\circ} \pm 5$ & $1.8^{b} \pm 0.1$ & $2.0^{a} \pm 0.1$ & $2.5^{b} \pm 0.1$ & $2.8^{b} \pm 0.1$ & $3.6^{b} \pm 0.1$ & $4.5^{b} \pm 0.1$ & $25.8 \pm 0.1$ & $26.8^{a} \pm 0.1$ & $9.3 \pm 1$ & $7.4 \pm 0.1$ & $57.03^{\mathrm{a}} \pm 0.1$ & $56.5^{b} \pm 0.1$ \\
\hline LS30 & $565^{c} \pm 1$ & $539^{c} \pm 1$ & $1,104^{c} \pm 5$ & $2.2^{a} \pm 0.1$ & $2 .{ }^{a} \pm 0.1$ & $3.0^{\mathrm{a}} \pm 0.1$ & $3.1^{a} \pm 0.1$ & $3.2^{c} \pm 0.1$ & $5.4^{a} \pm 0.1$ & $26.3 \pm 0.1$ & $26.4^{b} \pm 0.1$ & $9.2 \pm 0.1$ & $7.6 \pm 0.1$ & $56.1^{\complement} \pm 0.1$ & $55.5^{c} \pm 0.1$ \\
\hline L.S.D. & 5.9939 & 1.998 & 9.9898 & 0.1998 & 0.1998 & 0.1998 & 0.1998 & 0.1998 & 0.1998 & 0.1924 & 0.1999 & - & - & 0.2418 & 0.1974 \\
\hline Sunflower & $210 \pm 1$ & $170 \pm 1$ & $380 \pm 1$ & $1.9 \pm 0.1$ & $1.0 \pm 0.1$ & $8.0 \pm 0.1$ & $3.5 \pm 0.1$ & n.d & n.d & $12.0 \pm 0.1$ & $15.0 \pm 0.1$ & $1.8 \pm 0.1$ & $2.0 \pm 0.1$ & $76.3 \pm 0.1$ & $78.5 \pm 0.1$ \\
\hline Cottonseed & $250 \pm 1$ & $90 \pm 1$ & $340 \pm 1$ & n.d & n.d & $7.5 \pm 0.1$ & $7.0 \pm 0.1$ & n.d & n.d & $8.0 \pm 0.1$ & $8.0 \pm 0.1$ & n.d & n.d & $84.5 \pm 0.1$ & $85.0 \pm 0.1$ \\
\hline
\end{tabular}

AN: Anthroylnitrile; FSG: Free sterylglycoside and ASG: Acylated sterylglycoside

n.d: Not detected.

Each value is the mean \pm SD of three triplicate determinations.

Means in each column with different letters are significantly different $(p<0.05)$.

oils which is similar to SFO $(95.5 \% \quad \alpha-T)$. In addition, SFO and CSO had much higher tocopherol contents than the lettuce seed oils.

\subsection{Lypolysis}

Table 7 records the fatty acid composition of the original oil (triglyceride, LS30) together with those occupying the 2-position (monoglyceride). It is clear that the 2-position is mainly acylated by unsaturated fatty acids (98.6\%) namely oleic and linoleic acids. This fact is obviously in favor of the positional distribution rule in conventional vegetable oils.

\section{DISCUSSION}

Comparing the fatty acid profiles of the investigated oils (three lettuce seed oils, SFO and CSO) as determined by GLC it can be seen that lettuce seed oils were characterized by their high linoleic (C18:2, n-6) acid contents as compared to SFO and CSO and high oleic acid contents as compared to CSO. The total unsaturated fatty acid and polyunsaturated fatty acid (PUFA) contents of lettuce seed oils were about $88 \%$ and $61 \%$, respectively. This result is in agreement with those reported by (Mekki et al., 1998; El-Mallah et al., 2003 and Mekki and Orabi, 2007). A high concentration of PUFA is a positive attribute in the functional foods and the nutraceutical market. Moreover, according to the amount of $n-6$ in lettuce seed oil, it can be considered as a significant source of essential fatty acids. Concerning the saturated FAs, lettuce seed oils resembled those of SFO.

With regards to the triacylglycerol molecular species containing n-6 fatty acid, present in lettuce oils, they are characterized by their high content of LLL, LLO, LLP and they also contained high amounts of LOO which resemble those of SFO and CSO. This result is in agreement with those reported by El-Mallah et al., (2003).

Regarding the phytosterols (the four classes of sterol lipids, namely, sterol esters, free sterols, free and acylated sterylglycosides); they constituted

Table 6

Tocopherol profiles

\begin{tabular}{lccccc}
\hline \multirow{2}{*}{ Sample } & $\begin{array}{c}\text { Total content } \\
\left(\mathbf{m g ~ k g}^{-1}\right)\end{array}$ & \multicolumn{4}{c}{ Tocopherol distribution (\%) } \\
\cline { 3 - 6 } & $381^{\mathrm{c}} \pm 1$ & $100.0 \pm 1$ & & $\boldsymbol{\gamma}-\mathbf{T}$ & \\
\hline LS10 & $385^{\mathrm{b}} \pm 1$ & $100.0 \pm 1$ & & & \\
LS20 & $390^{\mathrm{a}} \pm 1$ & $100.0 \pm 1$ & & & \\
LS30 & 1.9980 & & & & \\
L.S.D & $670 \pm 1$ & $95.5 \pm 0.1$ & $2.6 \pm 0.1$ & $1.0 \pm 0.1$ & $0.9 \pm 0.1$ \\
SFO & $630 \pm 1$ & $44.8 \pm 0.1$ & n.d & $55.0 \pm 0.283$ & $0.2 \pm 0.01$ \\
CSO & & & & & \\
\hline
\end{tabular}

n.d: Not detected.

Each value is the mean $\pm S D$ of three triplicate determinations.

Means in each column with different letters are significantly different $(p<0.05)$. 
Table 7

Fatty acid composition of LS30 lettuce seed oil and the corresponding 2-monoglyceride

\begin{tabular}{lcccccc}
\hline & \multicolumn{5}{c}{ Component fatty acids (\% mol) } \\
\cline { 2 - 7 } & $\mathbf{C 1 6 : 0}$ & $\mathbf{C 1 6 : 1}$ & $\mathbf{C 1 8 : 0}$ & $\mathbf{C 1 8 : 1}$ & $\mathbf{C 1 8 : 2}$ & $\mathbf{C 1 8 : 3}$ \\
\hline $\begin{array}{l}\text { Total Triglyceride } \\
\text { (LS30 oil) }\end{array}$ & $0.7 \pm 0.1$ & $0.2 \pm 0.1$ & $3.4^{\mathrm{a}} \pm 0.1$ & $26.0^{\mathrm{a}} \pm 0.1$ & $61.5^{\mathrm{b}} \pm 0.1$ & $0.2^{\mathrm{b}} \pm 0.1$ \\
2-Monoglyceride & $0.6 \pm 0.1$ & $0.2 \pm 0.1$ & $0.6^{\mathrm{b}} \pm 0.1$ & $23.9^{\mathrm{b}} \pm 0.1$ & $74.2^{\mathrm{a}} \pm 0.1$ & $0.5^{\mathrm{a}} \pm 0.1$ \\
L.S.D & & & 0.2267 & 0.2268 & 0.2183 & 0.2267 \\
\hline
\end{tabular}

Each value is the mean \pm SD of three triplicate determinations.

Means in each column with different letters are significantly different $(p<0.05)$.

the major portion of the unsaponifiable matter in most vegetable oils (Gunstone et al., 1986). They possess a broad spectrum of therapeutic effects in animals and humans (Ling and Jones 1995; Moreau et al., 2002; Clark 1996; Kamal-Eldein and Appeleqvist 1996). In humans, the consumption of plant-derived sterols particularly $\beta$-sitosterol (the main sterol in lettuce oils) reduces blood pressure (Murui et al., 1994), serum cholesterol levels and the risk of chronic heart diseases (Gunstone et al. 1986 and Clark 1996). Phytosterols also serve as intermediates for the synthesis of hormonal sterols and related pharmaceuticals (Ling and Jones 1995). In addition, phytosterols, especially B-sitosterol, exhibit significant anti-inflammatory effects and antitumor properties (Ling and Jones 1995 and Clark 1996). Moreover, lettuce seed oil is rich in sterylglycosides in comparison with SBO and CSO. SGS are known to suppress the absorption of cholesterol and fatty acids in the intestine, i.e. they are considered to be a hypocholesterolemic component (Murui et al. 1994). With respect to tocopherol (vitamine E) constituents, the results were similar to those recorded (El-Mallah et al., 2003) in the respect that $\alpha-T$ was the only component found in lettuce seed oil, which has biological and nutritive effects. In addition, It was found that lettuce seed oil had $98.8 \%$ unsaturated fatty acids in the 2-position which is the case in conventional vegetable oils.

\section{CONCLUSION}

From the results it can be concluded that the oil lettuce plant resists draught and draught did not affect the different kinds of lipids present in its seeds. Also, its lipid profiles are in agreement with those of conventional vegetable oils. According to these results, the oil lettuce plant can be cultivated and irrigated every thirty days in the reclaimed soils to save fresh water consumption and help to close the gap in oil production. In addition, lettuce oil can be considered as a good source for functional food ingredients and may be a valuable source of dietary fat. This study highlighted the importance of lettuce seed oil compared with conventional vegetable oils.

\section{ACKNOWLEDGEMENT}

The authors are grateful to Dr T. Murui of Nisshen Oil Mills (Japan) for his cooperation in many ways and supplying some standard compounds and help received.

\section{REFERENCES}

Christie WW. 1973. The preparation of volatile derivatives of lipids. in Lipid Analysis. Chapter 4, Pergamon press, pp.85-102.

Clark J. 1996. Tocopherols and sterols from soybean. Lipid Technol. 8, 111-114.

El-Din Ahmed A, EL- Ghazouly Maged G, Abou Donia Amin H. 1987. Phytochemical Study of Lactuca Salinga L. Growing in Egypt. Alexandria J. Pharm. Sci. 1, 5-7.

El-Hamdy AH, Perkins EG 1981. High performance reversed phase chromatography of natural triglyceride mixtures: critical pair separation. J. Am. Oil Chem. Soc. 58, 867-872.

El-Mallah HM, El-Shami SM, Hassanein Minar MM. 2003. Studies of Lipid Profiles of Vitis Vinifera (Grape) and Lactuca Scariola (Oil Lettuce) Seed Oils in Comparison with those of Soybean Oil. Mansuora University J. Agric. Sci. 28, 3179-3187.

El-Mallah MH, Murui T, El-Shami SM. 1999. New trends in determining the authenticity of corn oil. Grasas Aceites. 50, 7-15.

El-Mallah MH, Murui T, El-Shami SM. 1994. Detailed studies on seed oil of silicornia SOS-7 cultivated at the Egyptain border of Red Sea. Grasas Aceites. 45, 385-389.

El-Shami S, Hassanein MM, Murui T, El-Mallah MH. 1994. Studies of changes in patterns of fatty acids, sterols and tocopherols of oil during seed maturation part 1: sunflower seeds. Grasas Aceites 45, 227-231.

Gunstone FD, Harwood LJ, Padly BF. 1986. The Lipid Hand Book. Chapman\& Hall. Cambridge. P. 571.

Kamal-Eldein A, Appeleqvist AL. 1996. The chemistry and antioxidant properties of tocopherols and tocotrienols. Lipids 31, 671-701.

Ling WH, Jones PJ.1995. Dietary phytosterols: a review of metabolism, benefits and side effects. Life Sci. 57, 195-206.

McClave JT, Benson, PG.1991. Statistics for Business and Economics, Max Well Macmillian International Editions. Dellen Publishing Co. USA, pp. 272-295.

Mekki BB, El- Kholy MA, Mohamed EM. 1998. Effect of Folair Application of Potassin-P and Plant Spacing 
on Seed Yield, Oil and Fatty Acid Contents of Prickly Oil Lettuce (Lactuca Scariola L.) $8^{\text {th }}$ Con.Agron. Suez Canal Univ. Ismailia, Egypt 28-29 Nov.

Mekki BB, Orabi SA. 2007. Risponse of Prickly Oil Lettuce (Lactuca Scariola L.) to Uniconazole and Irrigation with Diluted Seawater. Am. Eurasian Agric. Environ. Sci. 2, 611-618.

Moreau RA, Whitaker BD, Hicks KB. 2002. Phytosterols and their conjugates in foods: Structural diversity quantitative analysis, and health- promoting uses. Prog. Lipid Res. 41, 457-500.

Murui T, Wanaka, K, Kuriyama K. 1993. Determination of sterylglycosides as their 1- anthroylnitrile derivatives. Biosci. Biotech. Biochem. 25, 614-617.

Murui T, Yoshikawa M, Takeuchi H, Fujii S, Mizobuchi H.1994. Effect of sterylglycosides from soybean on lipid indices in the plasma, liver, and feces of rats. Biosci. Biotech. Biochem. 58, 494-497.

Official and Tentative Methods of the American Oil chemists society. $1980.3^{\text {rd }}$ ed. AOCS, Chicago, Illinois.

Osman F, Ashourm AE, Gad AM 1973. Glyceride structure of Egyptian vegetable oils. Planta Med. 24, 53-60.

Rafi A, Tufail MQ. 1991. Studies of Lactuca Scariola Seed Oil. Sci.Int. (Lahore) 3, 67-68.

Wanaka K, Murui T. 1992. Determination of sterols in edible oils and fats by HPLC with fluorescence labeling. Yukagaku, 40, 306-311.

Recibido: $13 / 2 / 12$ Aceptado: 22/8/12 